\title{
LA ALCALDIA-PRESIDENCIA Y LA FORMALIZACION DE SUS DECISIONES
}

\author{
352.0752 \\ por \\ Vicente Boix Reig \\ Secretario de primera categoria de Administración local
}

SUMARIO: I. LA ALCALDIA Y SUS COMPETENCIAS. GENERALIDADES: 1. LOS ORGANOS MUNICIPALES Y SUS COMPETENCIAS. 2. LAS COMPETENCIAS DE LA AlCaldfa: A) Sistemática de este estudio. B) La determinación del sujeto que encarna el órgano.-II. LA FORMALIZA. CION DE LA VOLUNTAD DE LA ALCALDIA. EL LIBRO DE RESOLUCIONES: 1. LA EXISTENCIA DEL LibRo de Resoluciones. 2. El Libro de Resoluciones de la Alcaldfa: validez y eficacia: A) Antecedentes. B) Contenido. C) Efectos. D) El dilema transcripción-inscripción.III. CONCLUSION.

\section{LA ALCALDIA Y SUS COMPETENCIAS. GENERALIDADES \\ 1. LOS ÓRGANOS MUNICIPALES Y SUS COMPETENCIAS}

Las leyes conceden a nuestras Corporaciones municipales una personalidad jurídica que opera a través de sus órganos. El Ayuntamiento Pleno, la Comisión Municipal Permanente y la Alcaldía son los tres órganos municipales de decisión.

La actuación de cualesquiera de estos órganos es imputada directamente a la personalidad jurídica municipal, existiendo una vinculación tan sustancial entre persona y órgano que se puede afirmar su identificación en cuanto a efectos jurídicos se refiere, y por 
lo tanto que la Corporación municipal, más exactamente el Ayuntamiento, es el sujeto de derechos por ser a quien el artículo 4 de la Ley de Régimen local concede la representación legal del Municipio.

Si el Ayuntamiento asume el actuar de todos y cada uno de esos tres órganos, o lo que es lo mismo, si la actuación de uno de estos órganos afecta a los otros a través de la imputación a la personalidad única, resultará de interés examinar los vínculos existentes entre ellos.

Para comprender los efectos y el alcance de la actuación del Ayuntamiento, conviene estudiar la calidad de la competencia de sus órganos, observando si la que les atribuye la Ley está asignada a cada uno de ellos de manera excluyente, o si por el contrario existe una fluida relación interorgánica que posibilita la asunción por uno de las competencias atribuidas en principio a los otros.

Observando a uno de estos órganos, la Alcaldía, vemos cómo el artículo 116, apartado $i$ ), de la Ley de Régimen local señala como competencia del Alcalde -y luego veremos el alcance de esta denominación- "dictar las disposiciones particulares que exija el mejor cumplimiento de los distintos servicios y ejercer todas las demás facultades de gobierno y administración del Municipio no reservadas expresamente al Ayuntamiento Pleno o a la Comisión Permanente y las que ésta le delegue» (1). Con esta cláusula residual cobran especial realce, en el contexto general de competencias de los órganos municipales, las de la Alcaldía que se detallan en el indicado artículo, máxime si consideramos que las funciones de la Permanente fijadas en el artículo 122 del propio texto se configuran como un numerus clausus, y que la cláusula residual contenida en la letra $l$ ) del artículo 121, que contempla las competencias atribuidas al Pleno, no es completamente abierta, ya que encierra tan sólo una remisión a cualquier competencia que a este órgano le venga atribuida expresamente por un precepto legal concreto (2).

Lo que ya no dice la Ley es la existencia o la viabilidad de un tránsito de competencias de un órgano a otro. Son excepciones a

(1) De Pedro y SAN Gil, en afunciones de los órganos de gobierno de las Corporaciones locales», en RevisTa de Estudios DE LA VIDA LOCAL, 1971, número 171, mantiene el criterio de considerar que en la letra legal les funciones del Alcalde son minúsculas dentro del conjunto de las funciones atribuidas a los diversos órganos decisorios municipales.

(2) Este criterio está desarrollado con mayor detalle en el capítulo III de mi libro Presupuestos de eficacia de la gestión urbanistica municipal, Madrid, Instituto de Estudios de Administración Local, 1975. 
este silencio la cláusula delegatoria de la Permanente a favor del Alcalde - artículo 116, $i$ ), de la Ley de Régimen local- y la cláusula ratificatoria contemplada en el siguiente artículo 123 y que se refiere a los supuestos de urgencia contemplados en el artículo 122, apartado $i$ ), sobre acciones judiciales a adoptar en casos de urgencia por acuerdos de la Permanente que debe ratificar con posterioridad el Pleno. Pero nada dice la Ley sobre la posibilidad de que una materia de la específica competencia del Alcalde pueda ser asumida por el Pleno o por la Permanente, o de que las competencias de ésta se ejerzan por el Pleno.

El Tribunal Supremo se ha mostrado ciertamente indeciso en la materia, e incluso contradictorio.

Así, la sentencia del Tribunal Supremo de 22 de diciembre de 1967 confirma la de la Audiencia, que dice:

aformando parte el Alcalde tanto de la Comisión como del Pleno, del hecho de que el acuerdo fuera adoptado por aquélla o por éste, cuando correspondiere hacerlo sólo al Alcalde, no se sigue vicio alguno para el acto, sino por el contrario y dado el carácter colegiado y deliberante de dichos órganos, una mayor garantía de acierto en la resolución».

Por otra parte, la sentencia del Tribunal Supremo de 30 de mayo de 1972 confirma la de Audiencia, que asimismo dice:

«como tiene declarado el Tribunal Supremo en gran número de sentencias que por bien conocidas no es preciso señalar, en los supuestos de competencia del Alcalde no se podrá alegar incompetencia de la Comisión Municipal Permanente, e incluso del Pleno, cuando estos organismos entraran en asuntos de la competencia de la Alcaldía, al formar parte de aquéllos la primera autoridad municipal».

Opuesta a la anterior doctrina, es en cambio la sentencia del Tribunal Supremo de 30 de abril de 1959, también confirmatoria de otra de Audiencia Territorial, en la que se dice:

«el estudio del contexto de los artículos 122 de la Ley de Régimen local y 123 del Reglamento de Organización, impone estimar la negativa, ya que ambos preceptos, que determinan numerus clausus las atribuciones que competen a dichas Comisiones (Permanentes), de igual modo y forma que los artículos 121 y 122, respectivamente, de las Ordenaciones 
citadas, señalan las funciones del Ayuntamiento Pleno, no comprende las relativas a la materia y cuestiones objeto de los acuerdos impugnados, que a tenor de los artículos $116, i)$, de la Ley invocada, y 121, 19), del mentado Reglamento, corresponde al Alcalde, $y$, por tanto, hay que concluir que los acuerdos recurridos fueron adoptados con evidente incompetencia del órgano municipal que lo tomó» (3).

Ante este panorama parece necesario afirmar que la postura que niega viabilidad a una fluidez interorgánica de las competencias específicamente asignadas a cada órgano es la de mayor nivel técnico, toda vez que si aceptáramos que el Pleno pudiera asumir las competencias de la Permanente y de la Alcaldía, habría que pensar en la existencia de un solo órgano de gobierno, el Pleno, que delegaría sus competencias en unos órganos cuya importancia sería de segundo grado. No parece corresponderse esto con el espíritu de la Ley, que sitúa en primer lugar las competencias de la Alcaldía; seguidamente y diferenciadas de éstas, las de la Permanente, y después las del Pleno, y que matiza, y mucho, en los propios preceptos las especificas relaciones interorgánicas que expresamente detalla.

Por otra parte, los compartimientos estancos se nos presentan además como una consecuencia natural de las características y peculiaridades de estos órganos: unipersonal de la Alcaldía, deliberante en sesiones secretas de la Permanente y deliberante en actuación pública del Pleno. Parece inadmisible que un Pleno público pueda resolver sobre materias que la Ley ha previsto sean decididas en deliberación secreta (todas las de la Permanente). Además, en el cuadro de materias que permiten un Pleno secreto (4) no se encuentran las propias de la competencia de la Permanente. Por añadidura hay también un claro deslinde material de las competencias de estos órganos: son normativas y planificadoras las del Pleno, de gestión económica y gobierno casuístico las de la Permanente, y gerenciales y ejecutivas las del Alcalde.

(3) En esta misma línea doctrinal se pronuncia también la sentencia del Tribunal Supremo de 21 de octubre de 1964.

(4) Las que puedan afectar al prestigio del Ayuntamiento o a asuntos personales de los miembros de las Corporaciones o de sus familiares, según el artículo 229,3 , del Reglamento de Organización. 


\section{Las Competencias de la Alcaldía}

\section{A) Sistemática de este estudio}

El planteamiento expuesto nos permite llegar a una primera conclusión, ya reducido nuestro campo de mira a la Alcaldía, y es que el tema de la delimitación de las competencias de este importante órgano municipal, que parece clara a nivel legal, se manifiesta contradictoria en nuestra práctica jurídica.

A la señalada cuestión previa sobre la intercambiabilidad de competencias entre los órganos de gobierno municipal, habrá que añadir, entrando ya en la materia específica de la Alcaldía, el problema de la determinación del sujeto que encarna el órgano municipal que examinamos. Y tras dejar esbozado este problema, podremos acometer en la segunda parte de este trabajo el análisis de ese singular reedio de formalizar la Alcaldía su voluntad, que es el Libro de sus Resoluciones, en el que centraremos nuestra atención.

\section{B) La determinación del sujeto que encarna el órgano}

El artículo 67 de la Ley de Régimen local señala que los Tenientes de Alcalde, por el orden en que hubieren sido designados, deberán sustituir al Alcalde en casos de vacante, ausencia, enfermedad o impedimento de cualquier clase. El artículo 71 de la misma Ley indica que también podrá nombrar el Alcalde, como auxiliares y con las facultades que expresamente les delegue, Alcaldes de Barrio. El artículo 124 de la misma Ley dispone que el Alcalde Pedáneo tendrá en su Entidad local menor las atribuciones que en dicha Ley se señalan al Alcalde. Por último, y dentro de la misma Ley, el artículo 127.4 establece que en la sesión constitutiva del Ayuntamiento, el Alcalde dará cuenta de las designaciones de Tenientes de Alcalde, $y$, añade, de cualquier otra designación y representación que interese fundamentalmente al Municipio.

Sobre los Tenientes de Alcalde, el Reglamento de Organización dispone en su artículo 17 que en el acto de su nombramiento se determinará por el Alcalde el alcance de la delegación que les confiera. Sobre los Alcaldes de Barrio, el artículo 26 del mismo Reglamento vuelve a señalar que tendrán las facultades que expresamente se 
les delegue, resaltando el siguiente artículo 28 que tendrán el carácter de autoridad. Por último, el artículo 22 de este Reglamento de Organización señala que el Alcalde podrá conferir delegación especial a uno o varios Concejales para determinado cometido o gestión, dentro o fuera de la localidad.

Podríamos encontrar en alguna norma especial otro tipo de designaciones a favor de figuras diferentes. Baste la referencia expuesta para resaltar que la Alcaldía como órgano admite, por delegación de su titular, su adscripción a favor de Teniente de Alcalde, de Alcalde Pedáneo, de Alcalde de Barrio y de Concejal. Pero en ningún precepto encontramos el alcance de la delegación. Este debe ser precisado en la Resolución que otorga la delegación, pudiendo también contemplarse el tema en un Reglamento interno del Municipio. Pero creemos que en la práctica este tipo de delegaciones quedan un tanto difuminadas.

Valgan estas ligeras consideraciones para alcanzar una conclusión de trabajo, abierta, al igual que la conseguida respecto a la cuestión previa de la comunicabilidad interorgánica de competencias, a revisión. Y es que en nuestra vida jurídica se nos muestra un tanto deteriorada la figura de la Alcaldía como órgano municipal, sobresaliendo tan sólo la figura del Alcalde, que es el titular originario de las competencias de este órgano de decisión. No pareciendo que exista base para discriminar con trato diferencial según que el Alcalde actúe -artículo 59 de la Ley de Régimen localcomo Jefe de la Administración municipal, o como Presidente del Ayuntamiento o Permanente, o como Delegado del Gobierno.

\section{LA FORMALIZACION DE LA VOLUNTAD DE LA ALCALDIA. EL LIBRO DE RESOLUCIONES}

\section{LA EXISTENCIA DEL LibRo de Resoluciones}

Si la competencia y el titular de la competencia de la Alcaldía son temas que pueden ofrecer confusión, y que se encuentran abiertos a mayores estudios, el índice de inseguridad aumenta cuando entramos en la cuestión del modo de formalizarse la voluntad de la Alcaldía, en la que vamos a centrar este estudio.

A nivel legal, el artículo 12 del Reglamento de Organización es terminante al declarar que las Resoluciones del Alcalde habrán de 
inscribirse en el Libro especial destinado al efecto, y que será abierto con los mismos requisitos del Libro de Actas (5). Resaltemos el empleo del término compulsivo «habrán» sobre la obligatoriedad de utilizar el Libro de Resoluciones como modo de formalizar la Alcaldía su voluntad.

Nuestra legislación no es sin embargo generosa en referencias al Libro de Resoluciones, y con excepción de su expresa consideración en el artículo 104 del Reglamento de Población y Demarcación territorial, no es fácil encontrar referencias expresas. Sí son, por el contrario, muchas las referencias a Decretos de la Alcaldía - por ejemplo artículos 260 y 309 del Reglamento de Organización-. Es de resaltar también que los artículos 233 y siguientes del mismo Reglamento de Organización, que estudian el régimen de los Libros de Actas, omiten el examen del Libro de Resoluciones.

En conclusión se puede afirmar que la formalización de la voluntad de la Alcaldía (los actos administrativos de la misma) tiene un cauce de expresión mediante su constancia en el Libro de Resoluciones. Se debe sin embargo añadir que no se encuentran en los textos legales las frecuentes referencias que serían de desear a tan importante prescripción. Es más, la omisión del Libro en los artículos 233 y siguientes del indicado Reglamento de Organización nos lleva a afirmar que nuestro Derecho positivo se nos manifiesta confuso, en cuanto a la formalización de las Resoluciones de los Alcaldes, en el Libro de Resoluciones.

No puede por ello sorprender la siguiente sentencia del Tribunal Supremo de 29 de enero de 1974. (Era un problema de prescripción de multas impuestas por el Alcalde). Dice:

«... En el presente caso no obran originales en el actuado procedimental, los Decretos impositivos de las multas, sin que resulten idóneas, para autenticar procesalmente la fecha en que se dictaron las notas o diligencias extendidas al dorso de los escritos de denuncia de la Policía municipal, firmadas por el Subinspector Jefe y expresivas de que por Decreto de la misma fecha de aquellas notas... se sancionó cada hecho respectivo, pues es materialmente imposible constatar en la fecha de un año actuaciones que se produjeron en el

(5) En este sentido se manifiesta el artículo 305 de la Ley de Régimen local. Más detalle encontramos en el artículo 169 del mismo texto, sobre la constancia motivada de las Resoluciones de los Presidentes de las Corporaciones provinciales en los Libros especiales destinados al efecto y abiertos con los mismos requisitos que el Libro de Actas. 
siguiente, circunstancia que provoca incertidumbre en cuanto a la realidad de fechas de aquellas notas... con la implicada contradicción en cuanto a fechas de los Decretos que incrementa la incertidumbre procesal respecto a su cronologia».

Si las normas legales pueden provocar por su laconismo y por la indicada omisión un notable desconcierto, parece que hay todavía mucha distancia para que se pueda llegar a alcanzar un razonamiento como el contenido en el Considerando que antecede.

Porque una cosa es la deficiencia del montaje legal, e incluso que se pueda opinar sobre el grado de invalidez del acto administrativo dictado por la Alcaldía y no reflejado en su Libro de Resoluciones, y otra cosa muy distinta que el Tribunal Supremo declare que "es materialmente imposible constatar en la fecha de un año actuaciones que se produjeron en el siguiente».

La única explicación viable a la indicada declaración es el hecho de que el Libro de Resoluciones se ha deteriorado tanto con el pasar del tiempo, que nos obliga a dudar incluso de que en algún momento haya tenido vigencia efectiva.

Como instrumento de eficacia, prácticamente no ha sido estudiado por la doctrina; y como medio para la constancia de la voluntad de la Alcaldía, elemento formal del acto administrativo, ha sido objeto del reseñado parco tratamiento legal y del indicado y contradictorio examen jurisprudencial. Cuando el 29 de enero de 1974 puede fundadamente formularse las declaraciones que hemos transcrito del Tribunal Supremo, se nos está planteando y ofreciendo un motivo de oportunidad para, cuando menos, esbozar los aspectos en los que se fundamenta la bondad de este instrumento del Derecho local, y la conveniencia de su rigurosa vitalización práctica. Y en definitiva para preguntarnos qué es el Libro de Resoluciones de la Alcaldía.

2. El Libro de Resoluciones de la Alcaldía: validez y eFicacia

\section{A) Antecedentes}

En nuestra Baja Edad Media ya encontramos disposiciones que prestan especial cuidado en ordenar fórmulas para dar firmeza a las resoluciones administrativas. Así, en el Título 15 del Libro $1 .{ }^{\circ}$ 
de las Ordenanzas Reales de Castilla, en las Leyes 21, 95 y 110 de las denominadas de Estilo, en la Ley 41 del Título 32 del Ordenamiento de Alcalá, y principal y concretamente en la Ley 7 del Título 19 de la Tercera Partida del Código de las Partidas. Ya en época más reciente, la Ley 3 del Título 2 de la Novísima Recopilación, y en general todo su Libro 7, referido al gobierno civil de los pueblos, reitera en Autos acordados, exigencias tendentes a dar carácter, firmeza y garantía a las disposiciones emanadas de las autoridades locales.

Llega a nuestros días esta necesidad de dar fijeza a las resoluciones de los Alcaldes, que lleva a BARRos (6) a señalar la necesidad de hacerlas "constar de modo fehaciente para conocimiento de quienes hayan de cumplirlas».

\section{B) Contenido}

La obligatoriedad de esta constancia en el Libro de Resoluciones se sanciona irreversiblemente en el artículo 12 del Reglamento de Organización. Pero ¿a qué resoluciones del Alcalde alcanza este precepto?

Alvarez-GENDín (7) distingue entre resoluciones de ejecución de acuerdos corporativos y las demás. En un primer bloque los Decretos de ejecución, que cuando son positivos son un simple elemento o condición de eficacia del acuerdo corporativo. Y sólo cuando el Decreto de ejecución es negativo constituye un acto administrativo de naturaleza propia, que produce unos efectos jurídicos singulares; en estos supuestos, al independizarse la decisión del Alcalde de su titular y producir efectos jurídicos en el medio municipal y contencioso-administrativo, debe considerarse el acto dictado como una manifestación de voluntad que precisa rodearse de formalismos que garanticen la firmeza del acto para garantía y estabilidad de los derechos posiblemente afectados. Consiguientemente los Decretos de ejecución negativos deben tener acceso al Libro de Resoluciones.

En un segundo gran bloque, comprende ALVAREZ-GENDfN el resto de las resoluciones dictadas por el Alcalde en el ejercicio de sus

(6) Barros, en Derecho Local de España, página 124. Madrid, Reus, 1951.

(7) Alvarez-Gendf, en aEl Libro de Resoluciones», Boletín del Colegio Nacional de Secretarios, 1952, páginas 367 y siguientes. 
competencias, y tal y como éstas se contemplan en el artículo 116 de la Ley de Régimen local; e incluyendo, por lo tanto, los Bandos. $\mathrm{Y}$ este segundo bloque debe tener su reflejo en el Libro de Resoluciones.

Se excluye, en conclusión, todo el género de providencias de los Alcaldes, de mero valor procedimental o de impulsión que no alteran las relaciones de derechos entre órganos, o entre órganos y administrados.

La importancia que el Libro debe tener en su contenido nos la da, por una parte, la cláusula residual abierta del artículo 116, i), de la Ley de Régimen local sobre materias de la competencia de la Alcaldía, que debe convertirlo en una pieza importante del montaje burocrático de la Administración municipal; es decir, de todas aquellas que al no ser repetitivas no determinan su inclusión en un Padrón que aprueba la Permanente, y que al ser aprobadas por el Alcalde y afectar a derechos de los contribuyentes, deben formalizarse en el Libro de Resoluciones; lo que lleva a este Libro buena parte del actuar municipal en su proyección impositiva. Consiguientemente, el Libro es un instrumento de gran interés para estructurar el montaje y la coordinación de servicios en una organización administrativa municipal de envergadura. En conclusión, el Libro es un medio de formalizar la voluntad de la Presidencia, exteriorizando ese elemento formal del acto administrativo, que nos lleva a meditar sobre los efectos jurídicos de un acto que adolece de él.

\section{C) Efectos}

Dice el artículo 48.2 de la Ley de Procedimiento administrativo que el defecto de forma sólo determinará la anulabilidad cuando el acto carezca de los requisitos formales indispensables para alcanzar su fin, o dé lugar a la indefensión de los interesados.

Los efectos jurídicos de la no inclusión de un acto del Alcalde en el Libro de Resoluciones no se pueden generalizar. En principio no parece viable fundamentar en esta omisión por ausencia de «requisito formal indispensable» una acción de anulabilidad, pues la existencia del Decreto, conste o no en el Libro, es una actuación formal suficiente para que la voluntad del Alcalde se ejecute. Pero cuando esa voluntad así declarada o ejecutada no sea fehacientemente demostrable en el extremo referente a su constancia escrita 
en la fecha en que el acto se realizó y afectó a terceros, es decir, en la medida en que la no constancia del Decreto en el Libro pueda provocar indefensión en los administrados o en otra persona jurídica pública, entonces sí se desatará el instituto de la invalidez del acto, y podrá perjudicarse éste postulando su anulación por la propia Administración o por los Tribunales.

Estos efectos jurídicos ofrecen una cierta singularidad en relación con esa figura tan propia de la vida municipal, como es la «advertencia de ilegalidad" y la "suspensión gubernativa de acuerdos municipales». Es más, la ejecutividad de los actos y acuerdos municipales está obligada por el artículo 361 de la Ley de Régimen local en relación con el artículo 292 del Reglamento de Organización. Sobre estas reglas del juego, resulta inviable instrumentar una advertencia de ilegalidad sobre un actuar no formalizado o sobre una omisión, y resulta imposible cumplir con la fiscalización gubernativa cuando el acto, del que por discriminación respecto a los acuerdos corporativos no hay que dar cuenta al Gobernador, ni es denunciado o cuando incluso ni siquiera se ha formalizado. En conclusión, si una resolución de la Alcaldía no se incorpora al Libro de Resoluciones, se debilita en sus garantías de autenticidad y firmeza, y debilita a su vez la eficacia de los controles de legalidad previstos con mayor o menor acierto por el legislador.

\section{D) El dilema transcripción-inscripción}

SÁENZ-LÓPEZ (8) se inclina por la «necesidad de transcripción literal, porque de no ser así no se cumplen las necesidades que produjeron su creación»..., es decir, "la necesidad de una perfecta autenticación".

Creemos que si lo que se persigue con la entrada de la resolución en el Libro es conseguir una garantía de autenticidad en cuanto al texto y a la fecha, habrá providencias en las que el literal sea jurídicamente de interés, y otras en que esto sea irrelevante. En principio debemos pensar que los Decretos con motivación singular deben ser transcritos al Libro, mientras que aquellos que sólo interesen en sus datos liquidatorios o en la fecha de la decisión - aprobatoria, bastará con su inscripción, es decir, con una escueta

(8) SÁenZ-LóPEZ, en La Fe pública administrativa en la Vida local. Madrid, Abella, 1966, página 79 . 
anotación que permita su fácil identificación, en la forma autorizada por el artículo 42 de la Ley de Procedimiento administrativo.

\section{CONCLUSION}

Interesa a la seguridad jurídica y conviene a la organización administrativa vivificar este Libro. No está de más que apliquemos al Libro la doctrina de la sentencia del Tribunal Supremo de 17 de enero de 1972, confirmatoria de otra de Audiencia Territorial que dice:

"Considerando que cuando para la realización de una obra se necesita la concurrencia de permisos de varias autoridades y organismos administrativos, cada uno con privativas y específicas competencias, en razón a las finalidades de interés público que, respectivamente, tutelen o cumplan tales permisos, se tramitan y conceden con independencia, aunque sea necesario que todas ellas concurran para que la obra pueda realizarse legalmente, siendo obligación de cada órgano administrativo velar por el cumplimiento de la exigencia que a él atañe».

La Alcaldía, como órgano decisorio municipal titular de competencias propias, precisa revestir sus resoluciones con las formas prescritas por el legislador, pues en otro supuesto nacen con un vicio que puede llegar a afectar a su misma validez jurídica. Necesidad, pues, del Libro de Resoluciones.

Conveniencia también de este Libro para una eficaz organización burocrática. El problema de la coordinación de servicios y de funciones encuentra un camino de solución en este Libro, entendido como instrumento administrativo que, por documentar todas las decisiones de acción, obliga a reflejar en él a la mayor parte de los expedientes municipales, que pueden así ser controlados en sus respectivos procesos a través de sus fases ejecutivas. 